\title{
Assessment of the new Reimbursement Act functioning between January-November 2012 and its impact on pharmacies and pharmaceutical industry and oncological treatment
}

\begin{abstract}
Introduction. The new Reimbursement Act introduced on 01.01.2012 aimed at improving the way the Polish healthcare system operates, as well as reducing and unifying the prices of medicinal products. The Act provides that the prices for reimbursed drugs are lowered and unified. Increase the transparency, increase the number of innovative reimbursed drugs and lowering the level of co-payments.

Aim. The authors analyze the influence of the new Reimbursement Act (introduced on 01.01.2012) over the way the Polish healthcare system works.

Material and methods. The contents of the Reimbursement Act (introduced 01.01.2012) were used as research material. A content analysis of the new Act (conducted between 2013 and 2014) and its impact over the pharmaceutical industry, drug wholesale and drugstores was analyzed.

Results. Some numerical data concerning retail margins, co-payments by patients, limit groups, reimbursed drug prices were showed in the study.

Conclusions. Unfortunately, the Act itself has many shortcomings, inconsistencies or vague entries that require urgent amendment. Hence, it had a totally different impact.
\end{abstract}

Keywords: new Reimbursement Act, co-payments, prices of reimbursed drugs, the pharmaceutical market.

DOI: $10.1515 /$ pjph-2016-0004

\section{INTRODUCTION}

On 1 January 2012, the new Reimbursement Act was introduced with the intention of regulating and making the market of reimbursed medicines and financial-medical procedures in healthcare system more transparent. It was assumed that each of the beneficiaries of the Act would receive regulations to facilitate the functioning in the structure of broadly understood health services, starting from drug manufacturers, wholesalers, through pharmacies, hospitals, patients, as well as the National Health Fund, doctors, warehouses. The Act changed the rules of purchasing medicines essential for patients treated on the wards, principles of operation of pharmacies and wholesalers. According to the Act, the list of reimbursed medicines should be updated every two months. Plus to that, pharmacists and physicians had to bear new responsibilities. In connection with the entry into force of the Reimbursement Act, changes in the reimbursement of medicines followed because of such regulations, e.g. relating to medical ordinance and prescriptions and rules for their implementation. The paper includes incomplete period of one year of the validity of the act i.e. January-November 2012.

\section{AIM}

The scope of interference in pharmaceutical law affected many branches of pharmacy, all medical professions, the prin- ciples of contracting agreements, the introduction of drastic financial penalties and solutions, which had not yet been used within broadly understood Polish health services. Therefore, the present paper presents an analysis of the current economic and legal consequences of the Act for the selected recipients: pharmaceutical industry, drug wholesalers and pharmacies. The authors looked at changes in reimbursed drug prices, both before the Act was introduced and in the period that followed.

\section{MATERIAL AND METHODS}

The authors of the study looked used the Reimbursement Act (introduced on 01.01.2012) which aimed at reducing and unifying the prices for reimbursed drugs, increasing transparency, increasing the number of reimbursed innovative drugs and reducing the copayments among patients. The authors analyzed the contents of the new Reimbursement Act and its influence over pharmaceutical industry, drug wholesalers and drugstores (the analysis was conducted between 2013 and 2014).

\section{RESULTS}

Until 2012, there had been two ways that drug reimbursement programs had been implemented in Poland. The Ministry of Health had been responsible for reimbursement lists, while the National Health Fund was responsible for reimbursing therapeutic programs, which concerned on the treatment 
of cancer patients. The drugs included in the list of reimbursed drugs (390 items in 2007) were divided into groups in which the active ingredient was the same molecule and the group in which the molecules are different but having similar indications, route of administration and the therapeutic effect (e.g., omeprazole and lansoprazole) [1]. In these groups, the same price limit was in force based on the cheapest preparation. The limit is the amount refunded by the NHF and the patient paid the difference between the price at the pharmacy and the limit. The following levels of payment were applied: $30 \%$, $50 \%$ and lump sum, and free of charge medications. Drugs that were not included in the list of reimbursed medicines and prescribed on the medical prescription were sold at full price (100\% payment) [2]. In the first quarter of 2007 patients contributed for reimbursed drugs $35.4 \%$; in the corresponding period of 2008 patients contributed $35.95 \%$ [3], in the period between January and November 2012, so after 11 months of the new Act being in force, patients contributed for reimbursed drugs as much as $38 \%$ [4]. These figures are alarming for Poland as the World Health Organization reports that the level of patient's level of co-payments for drugs exceeding the threshold of $40 \%$ is considered to be causing restrictions on access to medicines [5].

\section{DRUG PRICES}

Reimbursement Act introduced new regulations concerning drug prices. The changes happened on an unprecedented scale - no EU country had ever implemented changes of that kind before. The Act provided inter alia, for the official drug prices to be regulated, introduced rigid margins on reimbursed drugs that wholesalers and pharmacies had to abide by, as well as determined limit groups, which were a new method of calculating the pharmacy margin. Plus to that, the lists of reimbursed drugs were supposed to be published in an updated form every two months [6].

The Article 3 Paragraph 1 of the Act provides that the overall budget of the National Health Fund dedicated for reimbursement should not exceed $17 \%$ of the public funds reserved for the financing of guaranteed benefits in the financial plan of the Fund, which indicates the orientation of the legislature to make savings. The amount of the total budget for the refund will be equal to the amount of costs incurred in 2011 for guaranteed benefits in terms of health programs, in the section on drugs used in therapeutic and health programs and for the hospital treatment and outpatient specialist care in the section of chemotherapy drugs [7]. Between 2013 and 2015, the NHF budget will reach the 2011 level and only in 2015 it is supposed to be lower than it was in 2011 [6]. Hence, the legislator somehow freezes the expenses on reimbursement, allowing for some further savings on the part of the National Health Fund. The 2009 data can be used here for comparison. In that year, the National Health Fund spent some 18.9\% of total public funds on reimbursement, treatment programs and chemotherapy. This means, the expenses were reduced by up to $2 \%$ [2].

Four categories of drug availability were established: prescription drugs, in a drug program, as part of chemotherapy, and in the provision of guaranteed benefits other than the first three categories. The drug is distributed free of charge or for a fee: at a flat rate (3.20 PLN), for a $30 \%$ and $50 \%$ fee of the funding limit where the patient pays the difference between the limit price and the retail price, as it used to be before 2012 .
The payment for prescription drug was raised from the amount of 5 PLN to 7.50 PLN after 1 January 2012 and the possibility of prescribing of double amount of prescription medicine on one prescription with pharmacy taking two flat rate charges was abandoned [6].

Calculation of the pharmacy margin was hugely changed. At the moment, it is calculated using the wholesale price of the drug being a basis for the limit in this limit group at the level indicated in Article 7 paragraph 5 of the Reimbursement Act, and the entities entitled to the retail market are obliged to apply the margin established by law [6].

The novelty is that the official prices and margins are fixed. As a result, pharmaceutical wholesalers and pharmacies are not able to lower the price, even having received a discount from the manufacturer. The margin calculated on the limit is significantly lower than the margin charged on the wholesale price of the drug, which deteriorates the financial condition of companies that sell medicines. This situation is also unfavorable for hospital wards because they do not have the ability to negotiate prices with manufacturers and drug prices in hospitals are, in turn, maximum prices.

The Act introduces the concept of a limit group. It is now possible to create of separate limit groups and joint limit groups [6] (Article 15 Paragraph 3). In order to determine the limit, one must know the group of drugs belonging to the group as the basis for the limit. In addition, one must know the wholesale prices of drugs covered by the limit group to determine the highest from among the lowest prices and to know what the share of the drug is in trading quantity calculated by DDD (Defined Daily Dose) to see whether the drug meets the requirement of a $15 \%$ turnover. As it might be concluded, the methodology is very complex and is a very big obstacle to an effective work for hospital pharmacists.

There are some drugs prohibited for sale in Poland yet, they are brought into the country as part of targeted import, since they have received a positive decision on refunds earlier. In such cases, the margin is limited by law to $10 \%$ of the wholesale price but not higher than 20 PLN. Disabled veterans face a similar problem - in this case, the margin must not exceed the amount of 20 PLN [6]. An average pharmacy mark-up on drugs has decreased from 22 to $18 \%$ in case of reimbursed drugs [4]. Any error in the application of wholesale or pharmacy margin is subject to an administrative penalty

Upon entering of the Act into law, patients paid some 5.7\% less for drugs, as compared to 2011. The prices of non-reimbursed prescription drugs have decreased by $3.8 \%$. However, it caused a negative financial impact for patients, as increased co-payment for reimbursable medicines for patients and reduced the availability of medicines for the patient, because pharmacies significantly reduced storage and a big part of the drugs is available "on demand" for a given prescription, the more that many drugs dropped out from the reimbursement lists [4]. In addition, pharmacies wanting to cover losses arising from a reduction in margins raised retail prices for the OTC products by $6.3 \%$. As previously stated, the level of patient contribution for drugs increased to $38 \%$ [4].

The Act has also implemented a total ban on advertising of pharmacies. This means, pharmacies cannot utilize, loyalty programs, point cards or provide any discounts, bonuses or gifts to patients. It was a very important change for the pharmaceutical market. Since the introduction of the Act, drugs sold for a "nice price" have disappeared from the market. 
In case pharmacies commit any violations in this respect, they are fined with high administrative penalties. Thus, the Act could be said to have eliminated the grounds for competition between pharmacies. A total ban on advertising of medicines, even those sold without any discounts or reimbursement (priced $100 \%$ ) led to a decline in the competitiveness and hence the profitability of pharmacies and pharmaceutical wholesalers. Due to these changes, as many as $77 \%$ of pharmacies have reported a significant decline in profitability [4].

The decrease in sales of reimbursed drugs in 2011 by $18 \%$ in pharmacies and drop in pharmaceutical warehouses by $25 \%$ launched the "availability tourism", where patients seek drugs in other pharmacies, because pharmacies are unable to keep some drugs in stock [4].

The law imposes some administrative fines on the pharmacies, pharmacists and physicians. These penalties are quite severe and the fear of punishment caused discomfort in the work of a doctor and pharmacist. The responsibility for the insured patients has been transferred to pharmacists and doctors. Provisions of the Act destroy the essence of both the doctor's and pharmacist's profession - earlier, they were regarded professions of public trust. As of now, a conflict arises between doctor's or pharmacist's financial security and their obligations to the patients. It caused a pathological situation, where the doctor might be afraid to prescribe some reimbursed drugs to patients for fear of punishment that might be imposed by the NHF. The same thing applies to pharmacies with which the NHF signs a contract for implementing the reimbursed prescriptions with the owner and requires the pharmacy manager to sign a contract with the NHF [6].

This situation makes physicians prescribe the reimbursed drugs with $100 \%$ payment. By the end of November 2012, $8 \%$ of all prescriptions for reimbursed drugs were prescribed at full cost, $15.5 \%$ of prescriptions with a $100 \%$ cost are caused by the new Reimbursement Act and $17.8 \%$ of prescriptions with a $100 \%$ cost due to lack of contracts signed by doctors with the NHF [4]. By the end of November 2012, patients had spent some $42.7 \%$ more buying reimbursed drugs, as compared to 2011 [4]. In connection with the new situation of prescribing reimbursed medicines to eligible patients with a $100 \%$ payment there was established a non-monitored by the NHF segment of medicines called a segment, which the NHF cannot see in their system and it is the difference between expenditure on reimbursable drugs and the reimbursed drugs. Patients contributed about 700 million PLN to drugs in 2012 for two reasons: 200 million for the purchase of drugs from the list of reimbursed drugs but prescribed with $100 \%$ cost by the doctor, and 487 million for the purchase of the medicines with $100 \%$ cost, erased from reimbursement lists after January 1 [4]. The Act reduced the number of drugs in the list of reimbursed drugs by 1380 items compared to 2011 [4].

The market of prescription drugs was decreased by 2.7 billion PLN and the consequence of the decline in the dynamics of the pharmaceutical market is freezing of expenditures for research and development in pharmaceutical companies. The Act limited the possibility of refunds for hundreds of indications, which had a very negative impact on the pharmaceutical market [4].

\section{IMPACT ON THE PHARMACEUTICAL INDUSTRY}

For the first time in 20 years the pharmaceutical market (both hospital and pharmacy) has reported a decrease of ap- proximately $8.5 \%$, when compared to 2011 , i.e. 2.4 billion PLN [4]. In some pharmaceutical companies, the drop even reaches $35 \%$ and this applies mainly to innovative companies [4]. Companies making OTC drugs are doing better, since the law does not affect them. Yet, the advertising ban in pharmacies has had a negative impact on them too. The patients consumed 14\% less drugs in 2012 due to several factors [4]. At the end of 2011, before the Reimbursement Act was introduced, panic buying appeared, as in early January 2012 both physicians and pharmacists went on strikes. This made access to specialists more difficult and perturbations associated with the introduction of the Act appeared.

The generic companies and Polish drug manufacturers were most affected. Overall, drugs in Poland are $4 \%$ cheaper than in the rest of the EU and the innovative drugs are priced lower by $59 \%$ than in the EU [4].

A decrease in drug sales was accompanied by extra costs imposed on companies functioning on the Polish market. Based on risk-sharing agreements agreed upon with the Ministry of Health, companies in case of exceeding the NHF budget for reimbursed drugs will be forced to pay the so-called pay-back directly to NHF. Fortunately, in 2012 and 2013 companies will probably not pay the pay-back to the NHF because the budget for the reimbursement of medicines will not be exceeded. Currently, the biggest challenge for companies is to maintain the reference prices between Poland and other EU countries and preparing for negotiations with the Ministry of Health on lists of reimbursed drugs for the years 2014-2015.

\section{PHARMACEUTICAL DISTRIBUTORS}

Pharmaceutical distributors, after the Act was introduced, were forced to change the agreements with contractors, including about 14.000 pharmacies in a very short time. A reduction of wholesale margin from $9.78 \%$ to $7 \%$ made it necessary to cut down the costs and restructure the warehouses, leading to layoffs [4]. Compared with 2011, distributors reduced their stock by $12 \%$ [4]. In fear of a collapse of pharmacies, the distributors shortened payment terms to pharmacies which in many cases meant changing the rules of credit-limit trade and carefully kept the terms of payment for drugs and with each delay - they suspended delivery. The costs of distributors' operation in Poland are comparable to the costs of the warehouses all across the EU but drug prices in Poland are much lower. As a result, Polish wholesalers are least profitable in Europe, when it comes to net profit per unit of packaging. The wholesale margin has undergone two changes - it was decreased to $6 \%$ in 2013 and to $5 \%$ in 2014, which was also accompanied by a decrease of market dynamics which might have led to distribution problems and affect drug availability among patients [6].

\section{PHARMACIES}

In 2012, for the first time in many years, the number of pharmacies and pharmacy outlets in Poland has stopped growing Currently, there are about 14000 pharmacies in Poland and new ones open rarely. Seventy-seven percent of existing pharmacies reported staff shortages and numerous pharmacies have undergone ownership changes - they merged with other pharmacies or even closed [8]. These changes have made pharmacy chains (companies owning more than 5 pharmacies) gain a stronger position, as they accounted for $26 \%$ of the total number of pharmacies [4]. If the chain assumes including over 
2 pharmacies, so the networks constitute $45 \%$ of pharmacies in Poland [4]. Private pharmacies began to form so called buying groups to purchase OTC drugs and drugs paid at full cost with high discount and thus they improved their profitability.

The situation of specialist pharmacies located in specialized hospitals and clinics is especially difficult. Many of them are already unprofitable. The fixed margin introduced by the legislature for reimbursed drugs, which account for about $70 \%$ of the turnover in these pharmacies, is not enough to cover the operational costs [4]. New rules for calculating the pharmacy margin result in the fact that pharmacies selling expensive drugs hardly make any profit at all and even credit the NHF by waiting for two weeks for a refund. It is often heard that the NHF, after the amendment of the Act, pays refund to pharmacies late, extending the waiting time to 2 or even 3.5 weeks, which is caused by an intricate procedure of verification of reimbursement report. As a result, money of pharmacies is longer at the disposal of the NHF.

\section{CONCLUSIONS}

The idea behind the Reimbursement Act was to make the market more transparent and harmonizing Polish and European regulations. As a result, there are numerous disorders in the way the pharmaceutical market operates. Everyone involved in the new pharmaceutical law has suffered enormous costs to comply with the new guidelines. The idea was good, but vague rules and the difficulty in interpreting them necessitates the revision. The NHF was the biggest beneficiary of the Act - they gained influence over many decisions, received a large control by imposing penalties on doctors, pharmacists and hospitals. There are appeals against decisions of the NHF yet any appeals can be made to the NHF only. This means, there is a high risk of poor objectivity. The NHF, as a result of the introduction of the Act, has gained as much as 2 billion PLN and the purpose for which they needed that money remains unknown. Patients, due to concerns of physicians prior to writing the prescriptions for reimbursed drugs and penalties from the NHF were deprived of the right to drugs at a discount and purchased until December 2012 for about 500 million PLN drugs at full cost, which also contributed to savings of the NHF. Co-payment of patients has increased from $34 \%$ to $38 \%$ [4]. NHF, however, states that patients' payments in 2011 were at the level of $33.35 \%$, while in 2012 , at $33.06 \%$ [9]. The difference probably stems from the non-monitored by the NHF segment, i.e. the reimbursed drugs for which patients paid $100 \%$ payment. Certainly, the advantage of the Act is the introduction in 2012 of 620 new drugs both innovative and generic to the reimbursement lists [9]. There were added to the list, among others, innovative medicines such as: Insulinum glargine (Lantus), insulinum detemirum (Levemir), rivaroxaban (Xarelto), degarelix (Firmagon), denosumab (Prolia), dienogest (Vissane) [2].

While analyzing all the consequences of Reimbursement Act it can be concluded that it resulted in losses for consumers and especially for patients who, under the premise of the Act, were to be the beneficiaries. It has left a negative impact on the entire producer-patient chain.

It was mostly patients with chronic diseases that were affected by these changes. This pertains to oncological patients, asthmatics, diabetics and the pharmacies, especially those located in large oncology centers because of fears of purchasing expensive cancer drugs that may fall out of the lists or change the price. Other victims of the Act are innovative companies, and yet the patients were to have increased availability of modern treatment. Hospital market has also experienced a loss through the impact of the Act on Hospital Formulary. As a result, there was a chance that the drugs could be donated to hospital wards, such as those dealing with cancer after introduction of the Act, oncology wards cannot accept donation and the patient being treated must reside in the ward throughout the treatment period. Hospitals are not allowed to provide treatment requiring drugs exceeding the limit, as they would have to pay extra and run into debts. The Act has also prevented various charities from donating hospital wards. For instance, it affected the Great Orchestra of Christmas Charity in early 2012.

Both employees of hospital pharmacies and managers of oncology facilities should be careful when it comes to the size of packages of drugs used in the medication program. Medication programs since July 2012 have been treated as reimbursable medicines and have their official price and the refund by the NHF is based on EAN code (European Article NumberEuropean trade code) on the packaging of these drugs. It may happen that the drug purchased by the hospital in a larger and more economical package seemingly has a different EAN code than the reimbursed by the National Health Fund and will not be refunded.

As pointed out by McKenzie Legal Office, the Reimbursement Act has yet to be finished as a document and in a few points addressed to faulty recipients [10]. The range of refunds has not been fully determined, which limits the access to treatment [11]. The introduction of fixed prices and limit groups has really affected a patient at the pharmacy while purchasing prescription drugs. Also the patient has been deprived of the possibility of selecting a cheaper equivalent at the pharmacy, because if the equivalent is not cheaper than the price limit, the pharmacist cannot suggest it. Equivalents of drugs in the retail price lower than the price limit are usually formulations little-known to doctors and pharmacists.

Agreements between the Ministry of Health and pharmaceutical companies are malfunctioning as well. The Ministry did not have enough time to consider the offers of pharmaceutical companies and discussions were carried out chaotically. The option to negotiate the lowest possible sales prices of medicines by pharmaceutical companies was not exercised and the savings were made at the expense of patients by reducing the limits of subsidies for medications. Hospital treatment of cancer patients, chemotherapy and drug programs still remain a great unknown, for which the rules compatible with refundable drugs were applied.

All things considered, the Act was actually introduced with the intention of improving the reimbursement system but it has even deteriorated access to treatment and innovative therapies. Patients who have fallen under the Reimbursement Act are the biggest losers. In fact, the National Health Fund turns out to be the only beneficiary.

The authors of the Act seem to have lost control over the consequences that the Act had, both substantively and financially. The Act itself has many shortcomings, inconsistencies or vague entries that require urgent amendment. 


\section{REFERENCES}

1. Czech M. Farmakoekonomika i ocena technologii medycznych w gospodarowaniu lekami w Polsce. Warszawa: Oficyna; 2010.

2. [www.nfz.gov.pl]

3. Dopłaty pacjentów do leków refundowanych w I kwartale 2008. Lek w Polsce. 2008;8.

4. IMS POLAND.

5. [www.who.org]

6. Ustawa Prawo Farmaceutyczne uchwalona 12 maja 2011r przez Sejm, 26 maja 2011 roku popisana przez Prezydenta Dz. U. 2011 nr 122 poz.696.

7. [www.poia.pl]

8. Prezentacje prelegentów Health Project Management zamieszczone na stronie internetowej www.infozdrowie.org z dnia 11.12.2012.

9. [www.rynekzdrowia.pl]

10. [www.bacermckenzie.pl]

11. [www.gif.waw.pl]
Corresponding author

Prof. dr hab. n. farm. Dariusz Matosiuk

Chodzki 4A Str., 20-093 Lublin, Poland

Phone/fax 81-422 72 72;

E-mail: darek.matosiuk@umlub.pl 